\title{
Intervention Effects and Specificity Effects in Wh-questions
}

\author{
Min Jegal \\ (Kyungpook National University)
}

\begin{abstract}
Jegal, Min. (2017). Intervention Effects and Specificity Effects in Wh-questions. Language Research, 53.2, 343-378.
\end{abstract}

Specificity effects are a widespread phenomenon, both in overt and covert syntax, across all languages. This paper focuses on the cross-linguistic specificity effects found in overt syntax 1 ) and questions why the specificity property of a moved wh-phrase leads to immunity to syntactic constraints involved in "Intervention." I contend that a tendency for a specific phrase to override intervention effects lies in the inactiveness of its copy in the original position. This argument is supported by a large amount of empirical data: anti-reconstruction effects of specific wh-words and adjunction to outer vP-domain of specific quantifiers. When a wh-phrase is specific, its inactive original copy does not form a chain of movements, which permits the specific phrase to be out of the scope of a potential intervener in a relevant phase domain. This analysis is able to derive all specificity-related sentences that are free from intervention effects, thereby reconciling apparently conflicting examples

1) The specificity effects are more pervasive (universal) in overt syntax than in covert syntax. When a specific $w h$-word overtly moves, its movement is (almost) acceptable in syntactic constrained circumstances such as islands and Crossover. On the other hand, when a specific wh-word covertly moves, there are certaincases that disallow specificity effects. For instance, in Korean, a wh-in situ language, the specificity property of a wh-word does not offset weak crossover effects as demonstrated below.

(i) a. ${ }^{*} \mathrm{Ku}_{1}$-uy eomony-ka nuku 1 -lul sarangha-ni ?

he-Gen mother-Nom who-Acc love-Q

'Who ${ }_{1}$ does his 1 mother love?'

b. ${ }^{*} \mathrm{Ku}_{1}$-uy eomony-ka eonu sonyon ${ }_{1}$-ul sarangha-ni ?

he-Gen mother-Nom which boy-Acclove-Q

'Which boy ${ }_{1}$ does his 1 mother love?'

c. ${ }^{*} \mathrm{Ku}_{1}$-uy eomony-ka icung-eyse eonu sonyon ${ }_{1}$-ul sarangha-ni ?

he-Gen mother-Nom of these which boy-Acclove-Q

'Which of these boys ${ }_{1}$ does his ${ }_{1}$ mother love?'

For deeper discussions and details about overt-covert distinction with regard to specificity effects, refer to Jegal 2016. 
under existing feature-based analyses such as Rizzi's (2013) fRM and providing more consistent explanations on specificity effects.

Keywords: Specificity (D-linking), island, superiority, crossover, intervention effect

\section{Introduction}

The peculiarity of $\mathrm{D}$ (iscourse)-linked or specific phrases2) has been observed in a wide range of contexts involved in movements (e.g., island, superiority, and crossover contexts) in natural languages, particularly in English. A D-linked/specific wh-phrase tends to have a remedy effect on ill-formed sentences, so called, 'D-linking/ Specificity' effects. In other words, D-linked/specific phrases make otherwise ungrammatical sentences well-formed or better-formed.

Wh-islands

(1) a. ??Who do you wonder [when to meet ] ?

b. Which applicant do you wonder [when to meet__]?

c. Which of the applicants do you wonder [when to meet _ _ ]?

(Kiss 1993: 87)

(2) a. *Who did John wonder [whether Mary loved _ ] ?

b. ?Which man did John wonder [whether Mary loved__]?

(Boeckx \& Grohmann 2004: 245)

The sentences in (1) and (2) demonstrate circumstances known as wh-islands. A non-specific wh-word (e.g., who) is prohibited from being extracted from an island another wh-word produces, which yields the marginality of (1a) and (2a).3) Yet, when inherently specific wh-words

2) D-linking (Pesetsky 1987) and specificity (Enç1991) refer to the same notion in terms of the connectedness with sets established in previous discourse; I will mainly use 'specificity' throughout this paper.

3) The difference of acceptabilities between (1a) and (2a) seems to be associated with the presence/absence of tense within an island, but the tense itself does not determine 
(e.g., which man/applicant, which of the applicants) are extracted, the sentences are ruled in as in (1b-c) and (2b).4) The specific wh-elements are easily extractable compared with the non-specific one. That is, specificity leads to insensitivity to island effects.

This extractability of a specific $w h$-phrase is also found in superiority and crossover context. Let us examine examples in order.

\section{Superiority effects}

(3) a. Who did you persuade _ to read what?

b. ??What did you persuade who(m) to read _ ?

(Pesetsky 1987: 104)

(4) a. Which man did you persuade to read which book?

b. Which book did you persuade which man to read ?

(Pesetsky 1987: 106)

The sentences in (3) including non-specific wh-phrases, who and what, are subject to the Superiority Condition (Chomsky 1973) and/or the Minimal Link Condition (Chomsky 1995).5) The core concept of these conditions is that when an element moves, its movement must be performed as economically as possible; in multiple wh-questions, it is economical for the first $w h$-word to overtly move first to the left periphery. To

the degree of an island effect. I will not discuss this issue further since what we have to note in this paper is that a specific moved material provides amelioration effects on unacceptable sentences.

4) Pesetsky (1987) presents the degree of D-linking of wh-phrases as the following:

(i) Which-NPs are always D-inked.

(ii) Who, what, how many-NPs and adjunct wh-phrases could be D-linked.

(iii) Who the hell and what the hell are aggressively non-D-linked.

Wh-phrases that belong to the second group above (e.g., who/what-phrases) can serve as D-linked/specific elements if a proper context helps their specific interpretations. However, if no context is provided, they are typically regarded as non-specific. What this paper notes here is who/what-phrases are more infelicitous than which-phrases in the same sentences that is likely to be ill-formed; thus let us give attention to the contrast they display.

5) The MLC is a unified version of the Superiority Condition and wh-islands within the framework of Minimalist Program. 
illustrate, while the acceptability of (3a) lies in the cost-effective movement of the first wh-phrase who, the unacceptability of (3b) follows from the uneconomical movement of the second wh-phrase what. On the other hand, (4) containing specific wh-words exhibits the defiance to the Superiority Condition. If wh-participants in multiple wh-questions are both specific, the obedience of 'locality' appears not to be required.6)

Crossover constructions are also within the scope of specificity effects, as given below.

(5) Strong Crossover

a. ${ }^{*} \mathrm{Who}_{1}$ did the woman [he $\mathrm{e}_{1}$ loved] betray $\mathrm{t}_{1}$ ?

b. ?Which famous writer ${ }_{1}$ did the woman [he ${ }_{1}$ loved] betray $t_{1}$ ?

(Wasow 1972: 143)

(6) Weak Crossover

a. ?*[Who the hell $]_{1}$ do his $s_{1}$ students admire $t_{1}$ ?

b. (?)[Which famous professor $]_{1}$ do his ${ }_{1}$ students admire $t_{1}$ ?

(Falco 2007: 20)

In (5a) and (6a), the non-specific wh-phrases are prohibited from crossing over its co-referential pronoun, which is so called, 'Strong Crossover' and 'Weak Crossover' respectively. However, in (5b) and (6b), the prohibited crossover performance is somewhat permissible for the specific wh-phrase; consequently, these examples are more likely to gain the bound

6) Regarding multiple wh-questions that consist of only D-linked/specific wh-elements, Pesetsky (1987) and Pesetsky (2000) both attribute the insensitiveness to Superiority Condition that the sentences exhibit to the covert movement of a wh-in situ phrase (not to overt movement of a wh-phrase). To illustrate respectively, Pesetsky (1987) argues that D-linked wh-phrases do not undergo LF-movement and thus they do not yield offending ('cross') configurations that lead to unacceptability. Subsequently, Pesetsky (2000) claims that D-linked wh-in situ phrases undergo feature movements at LF and the feature movement of the first wh-in situ phrase can satisfy Superiority Condition. However, these arguments cannot be extended to D-linking/specificity effects found in islands and crossover structures. Thus, to account for all the specificity-related examples in a unified way, we first need to investigate properties of overtly moved specific wh-phrases. For more discussions on Pesetsky's (2000) analysis will be presented in section and for deeper discussions and more details, refer to Jegal (2016). 
variable reading than the examples in (a). ${ }^{7}$

All the data hitherto considered tell us that specific words tend to be impervious to Island effects, Superiority effects, and Crossover effects even though there is a greater or lesser degree of the amelioration effect. This observation is summed up as follows:

(7) $\left[\begin{array}{llll}\beta & a & \cdots & (\beta)\end{array}\right] a:$ a potential intervener

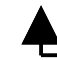

(i) When $\beta$ is not D-linked/specific, $\beta$ cannot cross over $\alpha$.

(ii) When $\beta$ is D-linked/specific, $\beta$ can cross over $\alpha$.

In (7), suppose that $a$ is an element that cannot be crossed over, i.e., a kind of "intervener" and $\beta$ is an element that moves in overt syntax. When $\beta$ is non-specific, it is not able to move past $\alpha$.

(8) When $\beta$ is non-specific in Island-, Superiority-, and Crossover-context, a. ${ }^{*}$ Who did John wonder [whether Mary loved $]$ ? $\beta$ a $\beta$

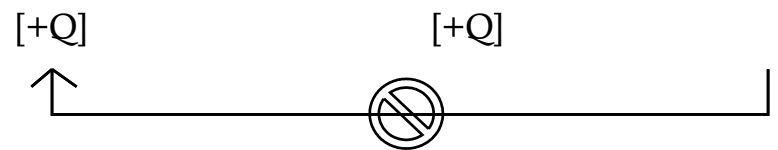

7) Unlike (5), in which the bound variable is situated inside the relative clause, simpler SCO examples where the bound pronoun sits in the head position appear to be irrelevant to the D-linking/Specificity effect:

(i) * $\mathrm{Who}_{1}$ does he 1 admire?

(ii) *Which famous writer ${ }_{1}$ does he ${ }_{1}$ admire?

In this paper, a co-referential pronoun is treated as a potential intervener of a co-referential wh-phrase in terms of feature sharing between them. Co-indexing is so powerful; co-indexed elements share exactly same features. Considering that the degree of feature sharing determines the strength of intervention effects, sharing completely identical features by co-indexing incurs 'the strongest intervention effects'. Besides co-indexing, the position occupied by an intervener has an impact on the degree of intervention effects. That is, whether an intervener c-commands an extracted element or not is important. In the case of WCO, even though co-indexed phrases are employed, with the help of the non-c-commanding position of a potential intervener, its intervention effect can be diminished by specificity (I classify this type of intervention effect as 'weak intervention effect'). Thus, this paper focuses on weak intervention phenomena, vulnerable to specificity effects. 
b. ??What did you persuade who(m) to read _ ?

$\beta$

$[+\mathrm{Q}]$ a

$[+\mathrm{Q}]$

个

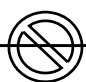

c. ?*[Who the hell $]_{1}$ do his $\underline{\text { W }}_{1}$ students admire $t_{1}$ ?

$\beta$

$\left[\varphi_{1}\right]$

a

$\left[\varphi_{1}\right]$

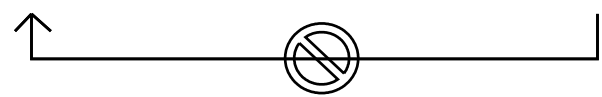

In these configurations, note that interveners are not arbitrarily determined. In a number of studies (S-S Kim 2002, Beck 2006, Rizzi 2013, S. Villata et al. 2016, etc.), it has been shown that an 'intervener' is described as an element that shares a set of identical features with a phrase that attempts to occupy a (semantically or syntactically) higher position than the potential intervener. Among others, according to Rizzi's (2013) revised featural Relativized Minimality (henceforth fRM), the degree of feature sharing between a crossing-over element and a crossed-over element determines how acceptable the relevant sentence is. In (8a) and (8b), the a-phrases (i.e., 'whether' and 'whom') are entitled to the interveners of the $\beta$-phrases (i.e, 'who' and 'what') since $\alpha$ and $\beta$ share $[+Q]$ features in each of the pairs. Likewise, in crossover contexts, given the fact that a $w h$-phrase and its co-indexed pronoun have a $[\varphi]$-feature marked as the same index, we can say that 'his' plays an intervening role on the movement of the wh-phrase.8) In this regard, I will treat the three contexts above as "intervention" phenomena.

On the other hand, when $\beta$ is specific, it is able to move past the offending element; that is, specificity effects obliterate intervention effects. By what kind of mechanism can specificity property of a wh-element override intervention effects? Can feature-based analyses on specificity effects, most representatively Rizzi's (2013) fRM approach, account for the three

8) Note that Rizzi (2013) did not deal with specificity effects observed in crossover examples. 
structures in a unified way? This is not the case as we will see below.

(9) When $\beta$ is specific in Island-, Superiority-, and Crossover-context, a. Which applicant do you wonder when to meet _ ?

$\beta$

$[+\mathrm{Q},+\mathrm{N}]$

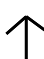

b. Which book did you persuade which man to read __?

$\beta$

$[+\mathrm{Q},+\mathrm{N}]$

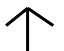

a

$[+\mathrm{Q}]$

c. [Which famous professor $]_{1}$ do his ${ }_{1}$ students admire

$[+\mathrm{Q},+\mathrm{N}]$

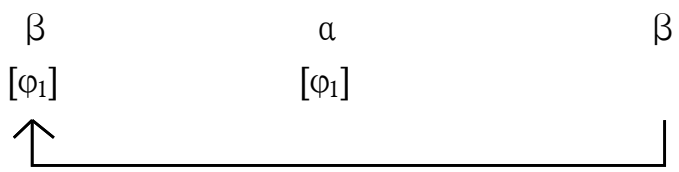

Rizzi's fRM account can cover (9a) but cannot elucidate examples like (9b) and (9c). In (9a), the feature specification of 'when' does not include that of 'which applicant'; as a result, the a-phrase cannot serve as an intervener. On the contrary, in (9b), $a$ and $\beta$ have $[+Q,+N]$ in common. In (9c), a shares the same $\varphi$-feature with $\beta$. The relationship of sharing identical features leads us to incorrectly predict those sentences to be ungrammatical like the sentences given in (8).

To solve this problem, this paper assumes that intervention effects should be evaluated during derivation, more exactly phase by phase, which is a distinctive approach from Rizzi's. In Rizzi's system, a representational approach, the surface copy of a moved element which sits on the left periphery must have more features than a potential intervener or have a set of completely different features from a set of features of the potential intervener. This approach cannot explain examples like (9b) and (9c). A different perspective is needed. Let us give attention to asymmetric behaviors between the non-specific and specific. Specific wh-phrases do 
not undergo reconstruction and specific quantifiers appear only in IP/TP domain, i.e. outer vP domain. Based on these different behaviors, I maintain that the contrastive results of the interplay between intervention effects and specificity effects in (8) and (9) are ascribed to distinctive movement configurations between the non-specific and the specific. For the specific, their copies in base positions (thematic position) are inactive, which contributes to transparency of a chain of movements. For this reason, specific elements are free from intervention effects in overt syntax. In contrast, for the non-specific, their base copies are active and their visible movements are susceptible to intervention effects.

Apart from this introductory section, the paper is organized as follows. Section 2 is devoted to discussions of Rizzi's fRM analysis and its problems. Section 3 analyzes intervention effects and specificity effects in a novel fashion to solve Rizzi's problems and propose that when a wh-phase is specific and moves overtly, its movement is transparent (or a chain of movements is not formed) since its base copy is inactive and the higher copy at the phase edge is only active. Section 4 provides empirical support to my proposal; first, specific phrases tend not to undergo reconstruction ('anti-reconstruction' effects). Second, in German and Dutch, specific quantifiers appear in outer vP-domain. Section 5 demonstrates that my analysis can extend to other islands. In Section 6, achieved results are briefly summarized.

\section{Intervention Effects}

2.1. Wh-island effects and Superiority effects

In overt syntax, $w h$-islands share with superiority effects in multiple wh-questions the property that two wh-elements are involved and the second wh-phrase cannot be extracted.

(10) $W h$-island effects $\quad: \cdots\left[\begin{array}{llll}\text { island } \mathrm{wh}_{1} & \cdots & \mathrm{wh}_{2}\end{array}\right.$ 
(11) Superiority effects : $\mathrm{wh}_{1} \cdots \mathrm{wh}_{2}$

cannot move

It has been suggested that the prohibition of extraction of the second wh-word is attributed to the intervention effect of the first wh-word in the two structures (Rizzi (1990, 2013), Pesetsky (2013), Hofmeister et al. (2013) and S. Villata et al. (2016)). Adopting this perspective, wh-islands and superiority-violating wh-questions will be considered as intervention phenomena. For a deeper and more extensive discussion on it, I introduce a widely acknowledged approach of reducing $w h$-islands to intervention effects. Rizzi (2013) argues that the degree of featural overlap between a target of movement and a potential intervener provides a measure of the degree of acceptability of an intervention configuration.

(12) Rizzi's (2013) featural Relativized Minimality * $\mathrm{X} \cdots \mathrm{Z} \cdots \mathrm{Y}$

A local relation (e.g., movement) cannot hold between $X$ and $\mathrm{Y}$ if $\mathrm{Z}$ intervenes and $\mathrm{Z}$ fully matches the specification of $\mathrm{X}$ in the relevant morpho-syntactic features.

(13) $\mathrm{Z}$ structurally intervenes between $\mathrm{X}$ and $\mathrm{Y}$ when $\mathrm{Z}$ c-commands $\mathrm{Y}$ and $\mathrm{Z}$ does not c-command $\mathrm{X}$.

As represented in (12), when an element moves from $\mathrm{Y}$ position to $\mathrm{X}$ position and its features completely match features of a potential intervener $\mathrm{Z}, \mathrm{Z}$ serves as an intervener. For instance, when the potential intervener has a full set of features of the target (i.e. full match), it incurs strong violation; when the feature specification of the potential intervener is included in that of the target (i.e. partial match), weak violation occurs, and a disjoint relation between them (i.e. no match) produces well-formedness. Let us take a look at these three types in order. 
(14) Bare Identity - Full match [+Q] $\mathrm{X}$ [+Q] Z $\quad Y$
a. ${ }^{*}$ What the hell do you wonder [who wrote _ ]?
b. ${ }^{*}$ What do you wonder [whether John could solve [+Q] $\mathrm{X}$ [+Q] $\mathrm{Z}$

The sentences in (14) yield severe ill-formedness since the featural specifications between the target (i.e., $[+\mathrm{Q}]$ ) and the potential intervener (i.e., [+Q]) are identical; the featural identity disrupts the local relations of $\mathrm{X}$ and $\mathrm{Y}$. This analysis of featural overlap can account for Superiority-violating examples as well.

(15)

$\begin{array}{ccc}{ }^{*} \text { What did you persuade } & \frac{\text { who }}{[+\mathrm{Q}]} & \text { to read } \\ \mathrm{X} & \mathrm{Z} & \text { ? }\end{array}$

The anomaly of (15) lies in the identical feature sharing between the two wh-elements; who blocks the chain connection of what and its base copy. As another case of full match, let us see the next example:

(16) Inverse Inclusion-Full match

${ }^{*}$ How do you wonder [which problem to solve

(Rizzi 2013: 177)

$[+\mathrm{Q}]$
$\mathrm{X}$

$$
[+\mathrm{Q},+\mathrm{N}]
$$

$\mathrm{Z}$
Y

In (16), the wh-phrase which problem has a full set of the features the extracted element how possesses, which is correctly predicted to block the dependency chain of how. Compared with the examples in (15), even if the featural specification of the intervener includes that of the extractee, as in (16), intervention effects arise although a target and a potential intervener do not share completely same features; 'Inverse Inclusion' rela- 
tion seems as deviant as 'Bare identity'.

The following example demonstrates the target and the intervener in (16) exchanges positions with each other, which induces a reversed result.

(17) Inclusion - Partial match ?Which problem do you wonder [how to solve __]

(Rizzi 2013: 177)

$$
[+\mathrm{Q},+\mathrm{N}]
$$

$\mathrm{X}$
$[+Q]$

$\mathrm{Z}$
Y

In (17), the blocking effect of the potential intervener weakens as its feature specification does not fully match (partially matches) that of the extractee; 'Inclusion' relation results in a 'weak' intervention effect.

A milder violation observed in (17) is tied up with the specificity effect. That is, specific phrases which are lexically restricted by a noun (they have $\mathrm{a}[+\mathrm{N}]$ as a part of the feature set) are more likely to pass through a potential intervener.

(18) No match

How do you think John could solve the problem __?

(Villata, S., et al. 2016: 4)

$[+\mathrm{Q}]$

$\mathrm{X}$
$[+\mathrm{N}]$

$\mathrm{Z}$
Y

The sentence in (18) is licit as there is no sharing feature between the extracted element and the potential intervener (here, John). The maximal distinction of a target from a potential intervener is the optimal case of circumventing intervention effects.

Above we have examined how well fRM predicts intervention configurations of feature overlap under a theory of intervention locality. However, (19) and (20), each of which involves an island effect and a superiority effect, is unexpected under the fRM analysis: 
Complex Identity:

(19) Which products do you wonder [which age-groups bought _ ]? (adapted from Kiss 1993: 93)

$$
[+\mathrm{Q},+\mathrm{N}] \quad[+\mathrm{Q},+\mathrm{N}]
$$

(20) Which book did you persuade which person to read _ ?

$$
[+\mathrm{Q},+\mathrm{N}] \quad[+\mathrm{Q},+\mathrm{N}]
$$

(Pesetsky 1987: 106)

In the featural representations of (19) and (20), the target and the potential intervener share the same features $[+\mathrm{Q},+\mathrm{N}]$; nonetheless, they are acceptable without causing intervention effects.

To account for these unexpected results, Villata, S., et al. (2016) made two assumptions: first, concerning lexically restricted elements, "which $\mathrm{N}$ can be attracted both by $[+\mathrm{Q},+\mathrm{N}]$ and by $[+\mathrm{Q}]$ ". Second, only attracting features are visible in the fRM system. Under these assumptions, (19) can be represented as the next configuration:

(21) Which products do you wonder [which age-groups bought _ ]? $[+\mathrm{Q},+\mathrm{N}]$

Villata, S., et al. (2016) describe (21) as the following: which age-groups is attracted by $[+\mathrm{Q}]$ head in the embedded clause and which products by $[+\mathrm{Q},+\mathrm{N}]$ head in the matrix clause. Then, the potential intervener in the embedded clause is less likely to block the extraction of which products since it owns a part of the feature set of the moved element. As a consequence, the case of 'complex identity', a case in which both wh-elements are lexically restricted or 'featurally complex', is reduced to 'Inclusion' relation, like (22) below.

(22) Which products do you wonder [who bought $[+\mathrm{Q},+\mathrm{N}]$ [+Q]

However, the analysis of bifurcated heads for restricted wh-elements (i.e., 
which-NPs) gives rise to a few questions. Why do we have to establish two kinds of attracting heads, $[+\mathrm{Q},+\mathrm{N}]$, or $[+\mathrm{Q}]$, for the same 'complex' wh-phrase (e.g., which book)? What triggers the separate settings for the probe of which-N? Villata, S., et al. (2016) limit targets attracted by a [+Q] head to only the lower complex wh-phrases in order to easily analyze 'Complex Identity' examples. Still, it remains unanswered why higher complex wh-phrases and lower complex wh-phrases have to be assigned non-uniform heads. Additional explanations or a novel analysis is required.

We have so far seen that wh-islands and superiority effects in multiple wh-questions can be reduced to intervention effects and sentences containing two specific wh-elements are predicted to be illegitimate under Rizzi's fRM, contrary to the fact. In section 3, I will present a new analysis to reconcile the apparently conflicting examples. Before that, it will be discussed in the following section that crossover effects are a kind of intervention effects and thus they are worth analyzing together with island, superiority contexts.

\subsection{Crossover effects}

In intervention contexts, whether an intervener sits in a head position (c-commanding position) or in a specifier position determines the degree of intervention. This rationale also corresponds to crossover contexts.

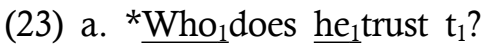

(* intended meaning: 'who is such that he trusts himself?')

b. ?* ${ }^{*} \mathrm{Who}_{1}$ does his ${ }_{1}$ mother trust $t_{1}$ ?

(?* intended meaning: 'who is such that his mother trusts him?')

c. Who does John trust

In strong crossover contexts as in (23a), a wh-phrase moves across its co-indexed pronoun that sits in the head position of a DP. The potential intervener in the c-commanding position strongly blocks the movement of the wh-phrase since the crossing-over element (i.e., who) and the 
crossed-over element (i.e., he) have the same $\varphi$-features in common due to co-indexation. On the other hand, in weak crossover contexts like (23b), a wh-phrase crosses over its co-referential pronoun in the specifier position of a DP. On account of the distinction of the position of a potential intervener, weaker intervention effects arise. That is why they are named 'Strong Crossover' and 'Weak Crossover' respectively. Lastly, in (23c), there is no intervener when the $w h$-phrase adjoins to Spec, $\mathrm{vP}$ since the proper noun John does not share any features with the crossing-over element. The different gradation in acceptability among the three sentences given in (23) reflects the fact that crossover effects are a subcase of intervention effects. In this paper, I will mainly deal with WCO effects because they exhibit more sensitivity to specificity effects which is worth discussing in terms of the correlation between intervention effect and specificity effects.

Let us go back to the 'specificity' issue. As we have briefly examined in section 1, Rizzi's fRM analysis cannot be extended to crossover examples since it wrongly predicts that they are always ungrammatical whether a wh-phrase is non-specific or specific. In other words, his feature-based account cannot capture the gradable difference of acceptability between the non-specific and the specific, as the following sentences demonstrate.

(24) a. $?^{*}[\text { Who }]_{1}$ do his 1 students admire $t_{1}$ ? $\left[\varphi_{1}\right] \quad\left[\varphi_{1}\right]$

b. (?)[Which famous professor $]_{1}$ do his ${ }_{1}$ students admire $t_{1}$ ? $\left[\varphi_{1}\right]$ $\left[\varphi_{1}\right]$

To put this in a nutshell, the feature-based analyses cannot elucidate all specificity-related examples and we need to analyze them from a different perspective. 


\section{A Unique Configuration of Specific wh-elements}

I argue that the overt movement of a specific $w h$-phrase should be depicted differently from that of a non-specific phrase because it has widely observed that a specific wh-element deters its copy in the original position from being active in overt and covert syntax. Inactiveness of the base copy is linked to transparency of movement operations and invisible movement chains are impervious to syntactic constraints such as intervention effects. This characteristic of overtly moved specific wh-phrases can not only elucidate counterexamples of Rizzi's fRM analysis pointed out in the preceding section but also provide a more consistent analysis on specificity effects found in overt syntax.

First of all, let us reexamine Rizzi's approach. In comparing features of two relevant elements in the intervention phenomenon, what we have to reflect on is which copy takes part in featural interactions.

(25) Rizzi's (2013) fRM

$$
\text { * } \mathrm{X} \cdots \mathrm{Z} \cdots \mathrm{Y}
$$

In configuration (25), $\mathrm{X}$ represents a final copy in the landing site and $Y$ represents a base copy in the original position. Rizzi (2013) takes into account featural interactions between target $\mathrm{X}$ and potential intervener $\mathrm{Z}$.

However, I turn focus to the relationships between a base copy and a potential intervener on the basis of the idea that we should evaluate the availability of intervention in the course of derivation, to be specific, in phase domains: vP and CP (Chomsky 2000, 2001).

(26) Evaluations on intervention in each derivation

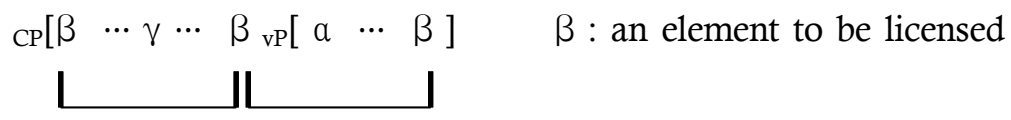

When $\beta$ is fronted to the left periphery of a CP through a Spec, vP, intervention effects are evaluated in each phase before the complement of a phase head ( $v$ and $C$ ) is transferred. If a intervenes $\beta$, the derivation 
will crash in the vP stage; even if a does not intervene $\beta, \beta$ will be evaluated with $\gamma$ in the CP phase. In this way, intervention phenomena should be analyzed under a derivational approach. What is an advantage of this new approach?

Many researchers (Comorovsky 1989, Kroch 1989, Rizzi 1990, Cinque 1990, Heycock 1995, Boecks 2003, Falco 2007, etc.) agree with the argument that specific elements lack reconstruction at LF. In other words, its base copy is not taken into account and instead or the intermediate copy at the phase edge or the surface copy at Spec, CP is counted. In addition, specific elements tend to occupy syntactically higher positions than nonspecific ones. For instance, specific quantifiers, in German and Dutch, do not appear in the inner $\mathrm{vP}$ domain but in the outer $\mathrm{vP}$ domain.9) Specific wh-phrases, in Hungarian, occupy the leftmost periphery in the $\mathrm{CP}$ domain, unlike non-specific ones. ${ }^{10)}$

Based on these non-trivial facts, I claim that the base copy of a specific element is inactive, which results in transparent movement operations. Under the assumption that evaluation on intervention effects is performed phase by phase, each successive cyclic movement of a specific wh-phrase does not form chains between the copies in that specificity is realized in a higher position within a phase/proposition. ${ }^{11)}$ See a given scenario.

9) Even though Diesing's (1992) mapping hypothesis focuses on quantifiers, I believe that the generalization thatspecific (presuppositional) interpretations arise in syntactically higher position can be applied to $w h$-phrases as well asquantifiers. Yet, note that I do not mean that wh-phrases and quantifiers must be treated as the same thing. More details will be discussed in section 4 .

10) Relevant Hungarian examples are as follows:

(i) *Hányszavazatotkireadtak le how many votes-Acc who to gave they PREF

'To whom did they give how many votes?'

(ii) Kirehányszavazatotadtak le Who to how many votes-Acc gave they PERF

'How many votes did they give to whom?'

(Kiss 1993: 97)

Hungarian is a language in which the surface order of operators corresponds to their scope. (i) is illicit since the inherently nonspecific wh-phrase 'how many votes' cannot occupy the wide scope position. In (ii), the preposed wh-phrase kire 'to whom', which is understood as specific with the help of the context, produces the well-formed sentence by taking wide scope slot.

11) Here, I adopt a theory of multiple spellout (see Uriagereka 1999 and Chomsky 2001), in which spell-out occurs in each phase, the vP and the $\mathrm{CP}$, unlike the traditional Y-model. 
(27) Step 1: intervention evaluation in $\mathrm{vP}$ domain ${ }_{\mathrm{CP}}\left[\begin{array}{lll}\beta 3 & \cdots & \beta 2_{\mathrm{vP}}[\end{array}\right.$

In (27), the base copy ( $\beta 1)$ is inactive and thus it does not take the evaluation test for availability of intervention of a potential intervener. The active copy ( $\beta 2)$ in Spec, vP is above the potential intervener a. As a result, this configuration does not give rise to intervention effects.

Next, let us suppose that an intervener sits between the Spec, vP and the Spec, CP.

(28) Step 2: intervention evaluation in $\mathrm{CP}$ domain

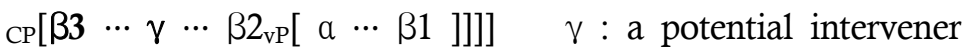

The only active copy of the specific element $\beta$ is the one in Spec, $\mathrm{CP}$, which is outside of the scope the intervener $\gamma$. Like (27), intervention effects cannot arise.

Thanks to the absence of intervention effects, the overt movement of a specific element has a remedy effect on infelicitous contexts. This perspective can rescue unexpected examples under Rizzi's analysis since all sentences containing a specific wh-phrase will be predicted acceptable under my analysis. The main argument is encapsulated as the following:

(29) When $\beta$ is specific and overtly moves,
$\left[\begin{array}{lllll}\beta & \cdots & a & \cdots & \beta\end{array}\right]$
$a:$ a potential intervener
$\vdots$
$\leftarrow$ transparent chain of movements
the inactiveness of its base copy results in a transparent chain of movements.

The inactiveness of base copies argued in (29) is supported by Sportiche's (2005) DP-split analysis. According to him, a D is not merged in thematic positions; that is, DPs are derived constituents. NPs merged in the base

$\mathrm{vP}$ (overt operations $\rightarrow$ covert operations) $\rightarrow \mathrm{CP}$ (overt operations $\rightarrow$ covert operations) $\rightarrow \mathrm{vP}$ (overt operations $\rightarrow$ covert operations) $\cdots$

12) $\beta 1, \beta 2$, and $\beta 3$ refer to the same copy. For clearer explanation, I assign different numbers to the copies. 
position do not participate in binding and scope relations. ${ }^{13)}$ The late insertion of a $\mathrm{D}$ that owns specificity feature suggests that specific elements can be realized in a higher position, not the original position.

To see clear pictures of the overt movements of specific elements and non-specific elements, let us examine configurations given below.

(30) a. When $\beta$ is specific and overtly moves, its base copy is inactive.

$$
\begin{aligned}
& \mathrm{CP}[\beta \cdots \diamond \operatorname{TP}[\cdots \mathrm{vP}[\beta \mathrm{vP}[\mathrm{a} \cdots \diamond \mathrm{VP}[\cdots \beta]]]]]^{14) \quad} \quad a: \text { a potential intervener } \\
& \beta>a \\
& \rightarrow \beta \text { is above } a(\beta \text { is intervention-free }) \text { in the } \mathrm{vP}-\mathrm{TP} \text { stage. }
\end{aligned}
$$

b. When $\beta$ is non-specific and overtly moves, its base copy is active.

$\mathrm{CP}[\beta \cdots \diamond \mathrm{TP}[\cdots \mathrm{vP}[\beta \mathrm{vP}[a \cdots \diamond \operatorname{VP}[\cdots \beta]]]]] \quad a:$ a potential intervener

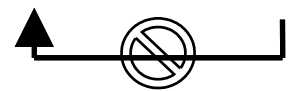

$\rightarrow$ The movement from the base position to the edge of $\mathrm{vP}$ is blocked by a before the vP-TP stage.

As stated in (30a), when the specific phrase $\beta$ overtly moves, moving past the potential intervener $a$ is not disturbed by the intervener because the base copy is not counted and it does not need to form a chain with its higher copy at Spec, vP. Consequently, the featural comparison between $\alpha$ and $\beta$ is unnecessary. This is a different part from Rizzi's approach. On the other hand, in (30b), the base copy of a non-specific word must be counted, which means their overt movements are not transparent unlike specific counterparts. Thus, the (il)legitimacy of the movement is determined according to a degree of feature sharing between $\alpha$ and $\beta$. Briefly, the configurations sketched in (30) brings a new perspective on intervention phenomena; which copy is counted is a crucial factor of determining the presence/absence of intervention effects and the acceptability of the

13) The relevant examples are demonstrated below.

(i) *The thief ${ }_{1}$ seems to Bill's mother to have escaped. $\mathrm{D}+\mathrm{N}_{1}$ seem to $\mathrm{X}_{1}$ 's mother to have $\mathrm{N}$ escaped.

(Sportiche 2005: 48)

The sentence above feeds Condition $\mathrm{C}$ since the DP, not $\mathrm{N}(\mathrm{P})$, is counted for binding relations.

14) $\diamond$-markers refer to the positions where 'transfer' operations take place. 
sentence.

From now, I will give details regarding benefits of the new analysis given in (29). The new type of configuration can account for the absence of intervention effects observed in wh-islands, superiority in multiple wh-questions and weak crossover structures in more unified way in that this analysis covers counterexamples of Rizzi's fRM. Those examples are repeated below.

(31) a. Which products do you wonder [which age-groups bought __]?

$$
[+\mathrm{Q},+\mathrm{N}] \quad[+\mathrm{Q},+\mathrm{N}]
$$

b. Which book did you persuade which man to read ? ?

$$
[+\mathrm{Q},+\mathrm{N}] \quad[+\mathrm{Q},+\mathrm{N}]
$$

c. [Which famous professor $]_{1}$ do his ${ }_{1}$ students admire $t_{1}$ ?

$$
\left[\varphi_{1}\right] \quad\left[\varphi_{1}\right]
$$

The 'full match' configurations are predicted as ill-formed sentences in Rizzi's system. However, the configuration for the specific, (30a), can resolve those examples in a straightforward way. Let us see wh-island and superiority structures first.

(31a)

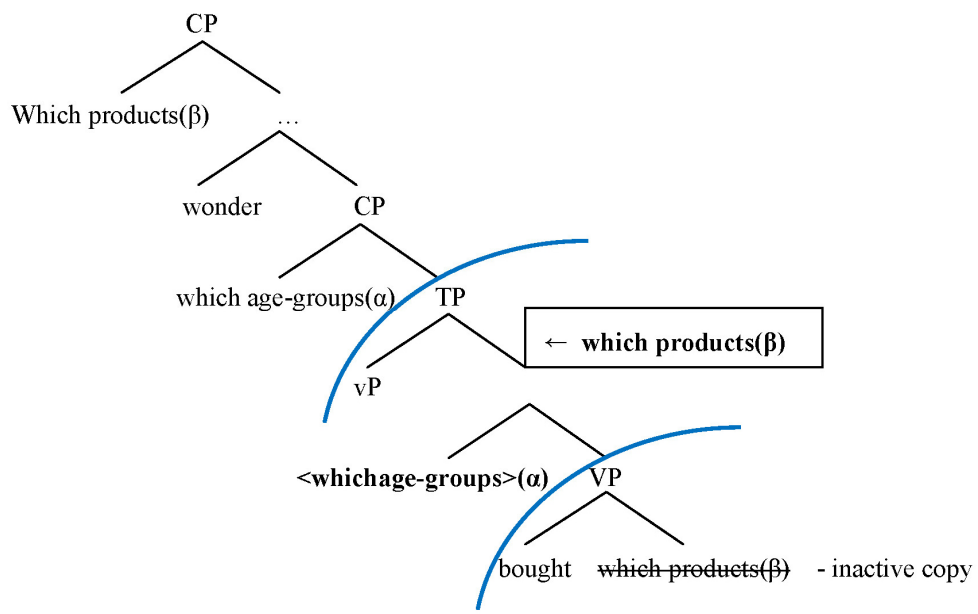


(31b)

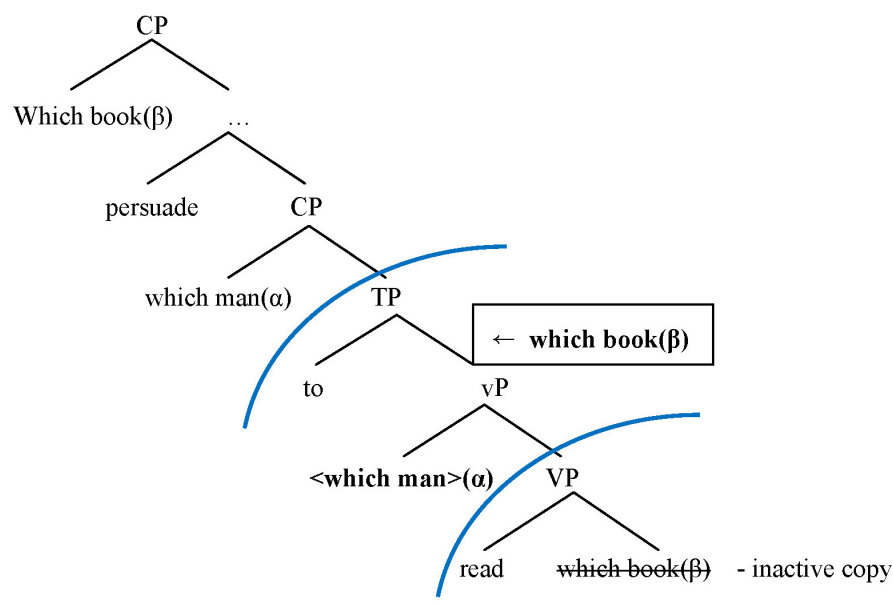

The two configurations above show the same situation in which overtly moved specific wh-phrases, which products and which book, do not provide their active copies in the base positions. Their movements from the original position to the Spec of vP are out of the area of "intervention". In other words, the interveners do not have their intervening targets within their c-commanding area. Accordingly, two specific wh-phrases in a sentence are not in competitive status; their features do not have to be estimated against each other. Thus, no occurrence of intervention effects is guaranteed in 'complex identity' contexts.

Plus, those sentences, (31a) and (31b), are strictly judged by some native speakers that they do not have $\mathrm{P}$ (air)-L(ist) reading. The unavailability of PL-interpretation implies that the object wh-phrase takes wider scope than the subject wh-phrase. The base copy of the object is deleted at LF as well as in overt syntax, which can account for wide scope interpretation of the object. The strict judgment on scope interactions is compatible with my analysis.

Now let us examine weak crossover examples. The asymmetry between the specific and the nonspecific in crossover constructions is also due to the inactive base copy of an overtly moved specific wh-phrase. 
(32) *? $\mathrm{Who}_{1}$ does his ${ }_{1}$ student admire $\mathrm{t}_{1}$ ?

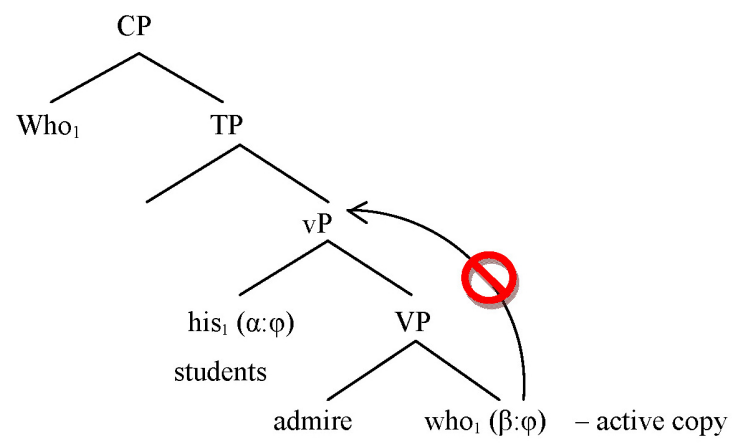

When the non-specific wh-word who moves to the Spec, vP, the movement is blocked by the co-indexed pronoun that shares the same feature $\varphi$ with the $w h$-phrase. The intervention effect of the co-referential pronoun yields the failure of derivation. As a concomitant, bound variable interpretation is impossible. How about a sentence containing a specific wh-phrase?

(33) Which famous professor ${ }_{1}$ does his $_{1}$ student admire $t_{1}$ ?

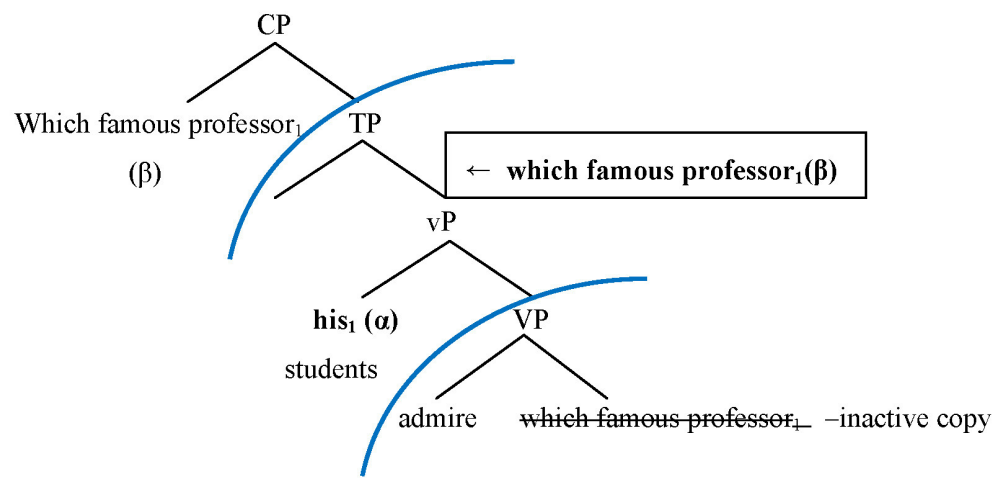

The base copy of which famous professor in the VP is inactive and thus the active copy of the wh-word isabove the potential intervener (its co-referential variable) at the edge of the vP; intervention effects do not arise.

As we have seen above, this new analysis is able to account for the specificity phenomenon found in overt syntax in a unified fashion. 


\section{Empirical Evidence on Higher Positions of Specific Elements}

\subsection{Anti-reconstruction effects of specific wh-phrases}

In this section, I will present supporting evidence of (29) in terms of the reconstruction asymmetry between specific and nonspecific cases. As argued by many researchers; non-specific wh-words undergo reconstruction while specific $w h$-words do not at LF under a theory of GB (so called, the 'anti-reconstruction effect'). Given the transition from the notion of 'trace' to that of 'copy', it can be described as this; specific elements do not leave their LF copies in situ (when they move overtly).15)

(34) a. [Which stories about Diana $]_{2}$ did she $e_{1}$ most object to $t_{2}$ ? 'There is a set of stories about Diana; what subset of that set did she most object to?'

b. *[How many stories about Diana $\left.]_{2}\right]_{2}$ is she $e_{1}$ likely to invent $t_{2}$ ? 'There is a number such that Diana is likely to invent that number of stories about Diana; what is that number?

(Heycock 1995: 558)

(34a) bleeds condition C effects. The whole phrase that occupies the left periphery, which stories about Diana, stays above its co-referential pronoun since it does not undergo reconstruction, which can circumvent the violation of Condition C. On the other hand, in (34b), the wh-phrase how many stories about Diana obtains nonspecific interpretation as the verb invent does not presuppose the existence of a familiar set for speaker and listener.16) The reconstruction for the nonspecific incurs the deviance of (34b); Diana

15) For more details of anti-reconstruction effects, see van Riemsdijk and Williams 1981, Comorovsky 1989, Kroch 1989, Rizzi 1990, Cinque 1990, Baylin 1999, Boecks 2003, Miyagawa 2006, and Son 2009.

16) In (34a) and (34b), the adjuncts that modify the extracted wh-elements contain R-expressions; thus it is important whether the adjunct can enter into the derivation or not after the extracted wh-element sits in the left periphery (without adjuncts). As Heycock (1995) points out, (34b) exemplifies the unavailability of the late merge of adjuncts. Given that adjuncts have a general property of undergoing late merge unlike arguments, we cannot explain the contrast in (34b) in terms of 'late merge'. In accordance with Heycock's (1995) idea, we have to take into account referentiality (specificity) of the extracted elements. 
is bound by she in the argument position after reconstruction, which feeds Condition $\mathrm{C}$ effect.

As Heycock (1995) points out, this asymmetric phenomenon between the two sentences in (34) is found within the same kinds of wh-phrases; to illustrate, how many-NPs display distinctive behaviors with regard to Condition C effects. Notably, how many-NPs have a potential of being connected with a pre-established set in interlocuters' mind; they are able to produce coreference reading like (34a). Let us compare the following examples below.

(35) a. *[How many lies aimed at exonerating Clifford $\left._{1}\right]_{2}$ is he planning to come up with $\mathrm{t}_{2}$ ?

LF: * $\left[\text { How many }<\text { lies aimed at exonerating } \text { Clifford }_{1}>\right]_{2}$ is $\mathrm{he}_{1}$ planning to come up with $[<$ how many $>$ lies aimed at exonerating Clifford $]_{2}$

b. [How many lies aimed at exonerating Clifford $]_{2}$ did he claim that he $e_{1}$ had no knowledge of $t_{2}$ ?

LF: $\sqrt{ }\left[\text { How many lies aimed at exonerating } \text { Clifford }_{1}\right]_{2}$ did he 1 claim that he $\mathrm{h}_{1}$ had no knowledge of $[<$ how many lies aimed at exonerating Clifford $\left._{1}>\right]_{2}$ ?

(Heycock 1995: 560)

In (35a), the embedded verb induces the non-specific reading of quantifying over amounts; specifically, the verb phrase come up with does not presuppose the existence of an actual set of lies, but requests information about a particular number or amount. This non-specific interpretation triggers a reconstruction effect; according to Heycock (1995), the whole phrase dose not reconstruct into the original position, only the remainder of the wh-phrase except the wh-head, as seen in the LF-representation above. On the other hand, in (35b), the embedded verb phrase had no knowledge of implies the specific reading of 'how many lies' since it is associated with the presuppositionality of a set of lies. The specificity of the wh-phrase rejects undergoing reconstruction and thus its higher copy can evade the Condition $\mathrm{C}$ effect. 
The status of specificity of the extracted phrase plays a significant role in determining Condition $C$ violation. ${ }^{17)}$ The specific do not obligatorily reconstruct; in other words, their base copies are not counted at LF. More relevant examples are listed below.

(36) Italian

a. Dimmi [quala dei colleghi di Maria $]_{2}$ pensi che 'Tell me [which of Maria ${ }_{1}$ 's colleagues] $]_{2}$ do you think lei $i_{1}$ abbia invitato $t_{2}$. she $_{1} \quad$ invited $t_{2}$.

b. *Dimmi [quanti colleghi di Maria $]_{2}$ pensi che 'Tell me [how many of Maria's colleagues] $]_{2}$ do you think lei $i_{1}$ incontrerà $t_{2}$ durante la carriera. she $_{1}$ will meet $t_{2}$ during her carreer.'

The Italian examples in (36) also exhibit the contrast the specific and the non-specific with regard to Condition C. In (36a), the past tense of the verb promotes presuppositional meaning of its complement, here the which-phrase, since the past tense presupposes the incidence of an act of invitation. The specificity of the wh-phrase forces the whole wh-phrase to stay high enough not to be bound by the pronoun co-indexed with the R-expression which is within the wh-phrase. Thus, this sentence satisfies Condition C. Contrastively, in (36b), the wh-phrase "how many of

17) There are certain cases in which the base copy of a D-linked/specific wh-phrase has to be counted to account for certain binding-involved examples.

(i) Which picture of himself did John think Fred liked (himself $=$ Fred, John)

(ii) John wondered which picture of him Fred liked. (him $=$ John, ${ }^{*}$ Fred)

In the examples above, Condition A and B seem not to be controlled by the specificity of the wh-phrase that contains a reflexive or a pronoun. As is well known, Condition A is referred to as 'somewhere' condition (Belletti and Rizzi 1988). Given that, the reflexive might activate the inactive copy in the original position. How about Condition B? In order to explain the disparity observed in the examples, we need to take into account the correlation between the binding principle and the specificity effect. If there is a hierarchy between constraints (under the Optimality theory), the hierarchy might give the answer about that. This, for now, is beyond my recent research. 
Maria's colleagues' entails non-specific reading because the uncertain future tense is incompatible with presuppositional reading. The reconstruction of the non-specific wh-phrase is compelled to occur, which will feed Condition C.

Moreover, the anti-reconstruction effect of specific phrases is found in crossover contexts as well.

(37) a. [Which students] $]_{1}$ does their ${ }_{1}$ professor think $t_{1}$ are in the great-hall?

b. ?*[How many soldiers $]_{1}$ does their ${ }_{1}$ commander think there are $t_{1}$ in the infirmary?

(Falco 2007: 34)

The fact that the weak crossover effect suspends in (37a) indicates that the specific wh-phrase serves as a successful binder of the co-referential pronoun. It implies that the LF-copy of which students is situated higher than the position its co-indexed pronoun exists. In contrast, in (37b) how many soldiers is non-specific since it is extracted in there-construction where nonspecific words only can appear. ${ }^{18)}$ For the nonspecific, the base copy takes part in LF-operations. The wh-phrase situated lower than the co-referential pronoun cannot serve as the antecedent of the binding relation.

Subsequently, scope reconstruction is also connected with the specific/nonspecific asymmetry. The following sentence illustrates this construction:

(38) a. [Quanti pazienti $]_{1}$ pensi che ognuno dei [How many parents $]_{1}$ (do) you think that every one of the medici riesca a visitare $t_{1}$ in un'ora? doctors can visit $t_{1}$ in one hour?

b. I think Doctor Brown could visit three patients in one hour, Doctor Smith five, $\cdots$

; Distributive reading (every $>$ how many)

18) In fact, how many-NPs can have nonspecific or specific interpretation according to contexts. 
c. Only three.

; Non-distributive reading (how many $>$ every)

(Falco 2007: 35)

How many-NPs can be interpreted as nonspecific and specific even in Italian. In (37a), the specific property of 'how many parents' determines the form of an answer: distributive or non-distributive reading. When 'how many parents' is recognized a nonspecific element associated with narrow scope, distributive reading like (38b) is obtained in which the every NP take scope over the base copy of the wh-phrase. In contrast, if 'how many parents' has a specific set known among interlocuters, sentence (38a) yields non-distributive interpretation like (38c). The specific wh-phrase has wide scope over the every-NP since its relevant LF-copy sits higher than the every-NP.

The anti-reconstruction effect of specific wh-elements has indicated that higher copies at least above $\mathrm{vP}$ (vP edge or TP domain) or in $\mathrm{CP}$ are selected at LF. The base copy is not employed at PF and LF. The unnecessary copy in the two interfaces does not have to be counted in testing syntactic constraints such as intervention effects.

\subsection{IP/TP-adjunction of specific quantifiers}

In the preceding section, a great amount of data has shown that an overtly moved specific phrase empowers its higher copy to participate in interpretation. The higher syntactic position for specific elements gains support from Diesing's (1992) Mapping Hypothesis that specific quantifiers are mapped into IP domain and nonspecific quantifiers into VP domain. In this section, I will introduce his idea and incorporate it into my analysis.

Diesing proposes that the IP domain is for specific reading on the evidence of the position for Quantifier Raising (QR). His Mapping hypothesis manifests that syntactic position is closely related to semantic interpretation. 
(39) Diesing's (1992) Mapping Hypothesis

Material from VP is mapped into the nuclear scope.

Material from IP is mapped into a restrictive clause.

The presuppositionality of a quantified DP necessarily induces $\mathrm{QR}$ to IP, thereby enabling the QP to be interpreted in IP. The QRed element obtains presuppositional reading in the restrictive clause which provides a restricted set for the quantifier. The quantifier binds all the variables established in the restrictive clause. On the other hand, DPs that stay in the VP domain are assigned existential reading by a process of existential closure in the area of nuclear scope.

For instance, the logical representation of a sentence containing a universally quantificational DP consists of three parts: an operator, a restrictive clause, and the nuclear scope.

(40) a. Every llama ate a banana.

b. Every $_{\mathrm{x}} \quad\left[\mathrm{x}\right.$ is a llama] $\left(\exists_{\mathrm{y}}\right) \mathrm{y}$ is a banana $\wedge \mathrm{x}$ ate $\mathrm{y}$

Quantifier restrictive clause

nuclear scope

(Diesing 1992: 7)

(40) is well-formed when every, as an overt operator, properly binds all values assigned on the variable $\mathrm{x}$ in the restrictive clause and the variable $\mathrm{y}$ is assigned a value that satisfies the nuclear scope.

In a nutshell, DPs associated with presuppositional interpretation obligatorily undergo QR to adjoin to IP, whereas DPs linked to non-presuppositional reading remain within the VP, not raised to IP. German and Dutch data provides empirical evidence for Diesing's tree splitting structure.

(41) German

a. '-weil jadoch zwei Cellisten in diesem Hotel abgestiegen sind since 'indeed' two cellists in this hotel have-taken-rooms

b. '-weil zwei Cellisten jadoch in diesem Hotel abgestiegen sind since two cellists 'indeed' in this hotel have-taken-rooms

(Diesing 1992: 78) 
In German, sentential particles such as 'indeed' can appear either to the left or to the right of the subject DP. (41a), in which the subject is in the $[\mathrm{Spec}, \mathrm{VP}]$ position, opts for existential (cardinal) reading. (41b), where the subject is placed in the [Spec, IP] position, yields presuppositional reading.

The indefinite subject in [Spec, IP] is mapped into a restrictive clause for "specific" reading.

(42) Dutch

a. Fred denkt dat [IP twee koeien op het dak liggen].

Fred thinks that two cows on the roof lie

'Fred thinks that two(specific) cows are lying on the roof.'

b. Fred denkt dat [IP er [vp twee koeien op het dak liggen].

Fred thinks that there two cows on the roof lie

'Fred thinks that there are two cows are lying on the roof.'

(Reuland 1988, cited from Deising 1992: 83)

The interpretation of bare plural subjects varies depending on their syntactic position. The VP-external position of the subject, as in (42a), does not allow existential reading; instead, "specific" reading arises. In (42b), the subject occupies the VP-internal position connected with the nuclear scope, which obtains existential reading.

The interrelation of IP/TP domain (syntactically higher position, compared with $\mathrm{vP} / \mathrm{VP}$ ) and specific interpretation has told us that specific quantifiers occupy higher positions in overt and covert syntax.

\section{Specificity Effects in Other Islands}

I argued in section 3 that a specific wh-element does not form a chain of movements. To explain further, the active copy of the specific is above the other element within a phase, which appears to confer easier extractability in movement operations. The prediction is born out in other island structures as well. 
Inner (Negative) islands

(43) a. How much did you pay __ ?

b. *How much didn't you pay _ ?

c. How much didn't you pay that you were supposed to _ ?

(Kroch 1989: 12)

Factive islands

(44) a. *Why do you regret that Tom fixed the radio _ ?

b. Which radio do you regret that Tom fixed ?

(Lee, G. 1996: 154)

In (43b), negation blocks the extraction of the non-specific wh-phrase 'how much'. In (43c), however, the extraction is permissible because the wh-phrase 'how much' turns specific with the help of the extraposed relative clause that provides presuppositional interpretation. ${ }^{19)}$ Meanwhile,

19) One might think that the following examples, especially (ib), are counterexamples of (43c); however, it is not.

(i) a. Which person didn't read which book?

b. *Which book didn't which person read

(Pesetsky 2000)

The unacceptability of (ib) is not because a specific wh-phrase ('which book') is prohibited from crossing over negation. Examine the next example.

(ii) Which book did which person not read

(Kiss 1986, Hornstein 1995)

As seen in (ii), a specific wh-phrase can undergo overt movement past negation, which means that overtly moved specific wh-elements are free from intervention effects. This aspect is well compatible with the analysis proposed in this article. If so, how can we explain (ib)? Regarding (ib), we need to examine covert movements of wh-phrases; the covert movement of the wh-in situ phrase ('which person') is blocked. Pesetsky (2000) describes the contrast given in (i) as follows: the legitimacy of (ia) follows from the fact that specific wh2-in situ phrase ('which book') undergo LF-phrasal movement which does not incur intervention effects. On the other hand, the illegitimacy of (ib) is due to the fact that specific wh1-in situ phrase undergo feature movement at LF and thereby an intervention phenomenon occurs. In short, feature movements incur intervention effects in that a $w h$-feature and its restriction are separated by an intervener. Here, what we have to note is that there is wh1-wh2 asymmetry with regard to covert movements even though a wh1-phrase and a wh2-phrase are specific phrases. Why do we have to assign different types of LF-movements to the same kind of wh-phrase (which-phrases)? This approach seems not to provide an economical explanation and furthermore to blur the boundary between the non-specific and the specific (some specific wh-words undergo LF-phrasal movements like non-specific ones). Jegal (2016) attempts a different approach to ac- 
(44) illustrates factive islands contexts; the deviance of (44a) is due to the fact that the non-specific wh-phrases (here, adjunct wh-phrase) cannot be extracted from factive islands, whereas the acceptability of (44b) is linked with the specific property of the extracted element.

In addition to weak islands, strong islands such as Complex NP islands, subject islands, and adjunct islands, are affected by the D-linking/specificity property of an extracted element even though the degree of a remedy effect is marginal (see Lasnik \& Saito 1992, Manzini 1992, Kiss 1993, Lee, G. 1996, Hofmeister, P. 2007 among others).

Complex NP islands

(45) a. *?What did you hear [a rumor that he bought

b. ?Which house did you hear [a rumor that he bought

(Kiss 1993: 96)

(46) a. I saw who Emma doubted [a report that we had captured in the nationwide FBI manhunt].

b. I saw which convict Emma doubted [a report that we had captured in the nationwide FBI manhunt].

$\rightarrow$ Acceptability judgments: $\mathbf{a}<\mathbf{b}$

(Hofmeister 2007: Fig. 3.1)

(47) a. I saw who Emma doubted [the report that we had captured in the nationwide FBI manhunt].

b. I saw which convict Emma doubted [the report that we had captured in the nationwide FBI manhunt].

$\rightarrow$ Acceptability judgments: $\mathbf{a}<\mathbf{b}$

(Hofmeister 2007: Fig. 3.2)

In (45) and (46), the NP type forming an island is indefinite NPs; in (47), the intervening NPs are definite NPs. In either group, specific elements yield the amelioration in acceptability compared with non-specific

count for the contrast between (ia) and (ib) without recourse to two different types of covert movements. For reasons of space, I would like to refer interested readers to Jegal (2016) as to further discussions. 
elements even though the degree of improvement is different depending on island forming NP types. According to Hofmeister (2007), it is more difficult for a certain wh-phrase to move out of definite NP-islands in comparison with the extraction out of indefinite NP-islands. What should be noted here is there is an asymmetry between the specific and the non-specific within the same environments (e.g., 'definite' barrier contexts or 'indefinite' barrier contexts) although specific phrases do not render island-violating sentences perfectly grammatical.

This phenomenon is also found in subject islands, as the following sentences demonstrate.

Subject islands

(48) a. How does [repairing the car ] bother you?

b. What the hell does [repairing __] bother you?

c. What does [repairing __ bother you?

d. Which car/ Which of these cars does [repairing _ ] bother you?

$\rightarrow$ Acceptability judgments: $\mathbf{a}<\mathrm{b}<\mathrm{c}<\mathrm{d}$

(Lee, G. 1996: 192)

The examples in (48) demonstrate that acceptability gradually increases from (a) to (d). To illustrate, the D-linked elements (i.e., which cars and which of these cars) are judged the most acceptable (or the least unacceptable) among them. This pattern discovered by Lee, G. (1996) is (partially) supported from formal experiments Hofmeister (2007) performed.

(49) a. Brendan acknowledged who it was possible that [our attempts to visit with __ had been misinterpreted by the press.

b. Brendan acknowledged which suspects it was possible that [our attempts to visit with __ had been misinterpreted by the press.

c. Brendan acknowledged which of the suspects it was possible that [our attempts to visit with __ had been misinterpreted by the press.

$\rightarrow$ Acceptability judgments: $\mathbf{a}<\mathrm{c}<\mathrm{b}$

(Hofmeister 2007: Fig 3.11) 
The same phenomenon is repeated in adjunct islands as presented in (50) and (51).

Adjunct islands

(50) a. How was Mary so happy [because Mickey read the storybook _ _ ?

b. What the hell was Mary so happy [because Mickey read _ ]?

c. What was Mary so happy [because Mickey read _ ] ?

d. Which storybook/Which of these strorybooks was Mary so happy [because Mickey read $]$ ?

$\rightarrow$ Acceptability judgments: $\mathrm{a}<\mathrm{b}<\mathrm{c}<\mathrm{d}$

(Lee, G. 1996: 192)

(51) a. I knew who my boss said she was calm [before meeting _ in the White House yesterday].

b. I knew which staff members my boss said she was calm [before meeting __ in the White House yesterday].

c. I knew which of the staff members my boss said she was calm [before meeting __ in the White House yesterday].

$\rightarrow$ Acceptability judgments: $\mathrm{a}<\mathrm{b}<\mathrm{c}$

(Hofmeister 2007: 95)

In this section, we have seen that weak islands and strong islands both show specificity effects even though the degree of amelioration effect of specificity is different in respective island situation. More important is that specific elements are easily able to be away from the edge of an island. This observation is well compatible with my new approach on specificity effects.

\section{Summary and Concluding Remarks}

Specific effects are one of surprising phenomena in linguistics that has pursued 'economy' because specific elements yield acceptability even 
though they do an uneconomical operation ('amelioration effects'). This paper has mainly dealt with specific wh-phrases that move in islands, superiority, and crossover structures, i.e., the specificity effects in overt syntax. To account for this phenomenon in a unified way, I focused on asymmetric behaviors of the non-specific and the specific with regard to reconstruction, surface position of quantifiers and the order of multiple wh-phrases. To illustrate, specific elements are not reconstructed to the original position and occupy higher positions (more concretely, outer vP domain or the edge of $\mathrm{vP}$ ) compared to non-specific counterparts. Based on this fact, the movement configurations of specific wh-phrases should be depicted in a distinctive manner from non-specific ones. Unlike non-specific elements, specific wh-words do not provide active copies in the base position, which suggests they do not form a chain from the base copy to the intermediate copy thereby being insensitive to syntactic movement constraints. That is, specific wh-phrases are immune to intervention effects via their transparent movements. This novel analysis provides several non-trivial advantages in the issue of specificity and intervention. First, it can account for specificity effects found in separate constructions (e.g., islands, superiority, and crossover) in a consistent fashion. In fact, previous researchers have not attempted to analyze the three relevant structures with a single tool. This paper incorporates them into intervention phenomena and more notably, first attempts to analyze crossover effects as a kind of intervention effect in literature. Second, as a concomitant result, it can cover counterexamples of Rizzi's (2013) fRM analysis. Last and most importantly, specificity effects are still under the economy principle.

\section{References}

Beck, Sigrid. (2006). Intervention Effects follow form Focus Interpretation. Natural Language Semantics 14: 1-56.

Boeckx, Cedric. (2003). Islands and chains: Resumption as stranding. Amsterdam: John Benjamins.

Boeckx, Cedric, and Grohmann, Kleanthes K. (2004). Submove: Towards a Unified Account of Scrambling and D-linking. D.Adger et al. (eds.), 
Peripheries: Syntactic Edges and their Effects, 241-257. Kluwer Academic Publishers. Printed in the Netherlands.

Chomsky, Noam. (1973). Conditions on transformations. In: Anderson, S.,

Kiparsky, P. (eds.), A Festschrift for Morris Halle. Holt, Reinhart and Winston, New York, 232-286.

(1995). The Minimalist Program. Cambridge: MIT Press.

Chomsky, N. (2000). Minimalist Inquiries: the Framework. In R. Martin, D. Michaels \& J. Uriagereka (eds) Step by step. Cambridge, MA: MT Press, 89-156.

Life in Language.

(2001). Derivation by Phase. In M. Kenstowicz (ed.) Ken Hale: A

Cambridge, MA: MT Press, 1-52.

Cinque, G. (1990). Types of $A^{\prime}$-dependencies. Cambridge: MIT Press.

Comorovski, I. (1989). Discourse-Linking and the WH-Island Constraint. In

Proceedings of the Nineteenth Annual Meeting, NELS.GLSA, University of

Massachusettes, Amherst.

Diesing, Molly. (1992). Indefinites. Cambridge: MIT Press.

Enç, Mürvet. (1991). The semantics of specificity. Linguistic Inquiry 1-25.

Falco, Michelangelo. (2007). Weak crossover, specificity, and LF chains. In Coreference, Modality and Focus, ed. Luis Eguren and Olga Fernández-Soriano, 19-44. Amsterdam: John Benjamins. URL http://ling.auf.net/lingbuzz/000668. Heycock, Caroline. (1995). Asymmetries in reconstruction. Linguistic Inquiry 26: 547-570.

Hofmeister, Philip. (2007). Representational complexity and memory retrieval in language comprehension. Doctoral dissertation. Stanford University, Standford, CA. Hofmeister, P., Florian, J.T., Sag, I.A., Arnon, I., and Snider, N. (2013). The scope ambiguity problem: distinguishing effects of grammar and processing on acceptability judgments. Lang. Cognitive Proc. 28.1: 48-87.

Hornstein, Norbert. (1995). Logical Form: From GB to minimalism. Oxford: Blackwell.

Jegal, Min. (2016). Crossover, Intervention and Specificity Effects. Doctoral dissertation. Kyungpook National University.

Kim, Shin-Sook. (2002). Questions, Focus, and Intervention Effects. In: Kuno, S., et al. (eds.) Harvard studies in Korean Linguistics 6, 520-533.

(2002). Focus matters: Two type of intervention effect.

Proceedings of WCCFL 21, Paper presented at the $21^{\text {st }}$ West Coast Conference on Formal Linguistics.

Kiss, Katalin E. (1986). Against the LF-Movement of WH-phrases. MS., 
Hungarian Academy of Sciences, Budapest.

Kiss, Katalin E. (1993). Wh-Movement and Specificity. Natural Language and Linguistic Theory 11: 85-120.

Kroch, Antony. (1989). Amount quantification, referentiality, and long wh-movement. Manuscript, University of Penssylvania.

Lee, Gunsoo. (1996). From referentiality to syntactic dependencies, Doctoral Dissertation, University of Wisconsin-Madison.

Miyagawa, Shigeru. (2006). On the "Undoing" Property of Scrambling: A Response to Boskovic. Linguistic Inquiry 37.4: 607-624.

Pesetsky, David. (1987). Wh-in-Situ: Movement and Unselective Binding. In Eric Reuland\& Alice terMeulen (eds.) The representation of (in)definiteness, 98-129. Cambridge, MA: MT Press. (2000). Phrasal Movement and its kin. MIT Press, Cambridge, MA.

(2013). Lisa Lai-Shen Cheng \&Nobert Corver (eds.). Diagnostics in Syntax. Oxford University Press. 123-157.

Reuland, Eric J. (1988). Indefinite Subjects. In Proceedings of NELS 18, 375-394.GLSA, University of Messachusetts, Amherst.

Rizzi, Luigi. (1990). Relativized Minimality. Cambridge: MIT Press. (2013). Locality. Lingua 130, 169-186.

Son, Gwangrak. (2009). A Derivational Approach to Wh-Scrambling. 영미어문학 제90호 3, 175-192

Sportiche, Dominique. (2005). Division of labor between Merge and Move: Strict locality of selection and apparent reconstruction paradoxes. In Proceedings of "Division of Linguistic Labor": The la Bretesche Workshop. Available at http://ling.auf.net/lingbuzz/000163.

Szabolcsi, Anna. (2006). Strong and weak islands, In The Blackwell Companion to Syntax, Vol. 4, eds M. Everaert and H. van Riemsdijk (Malden, MA: Blackwell Publishing), 479-532.

Uriagereka, Juan. (1999). Multiple spell-out. Groninger Arbeiten zur germanistischen Linguistik 40, 109-135

Villata, S., et al. (2016). Intervention effects and Relativized Minimality: New experimental evidence from graded judgments. Lingua (2016), http://dx.doi.org/10. 1016/j.lingua.2016.03.004.

Wasow, Thomas. (1972). Anaphoric relations in English. Doctoral Dissertation, MIT. Reorganized and revised published as Wasow 1979. 
Department of English Language and Literature Kyungpook National University

80 Daehakro, Bukgu, Deagu

E-mail: 177117now@gmail.com

Received: July 1, 2017

Revised version received: August 14, 2017

Accepted: August 28, 2017 